\title{
TRAJETÓRIA DE CONSTRUÇÃO DA CHAMADA PÚBLICA DE ASSISTÊNCIA TÉCNICA E EXTENSÃO RURAL INDÍGENA
}

\author{
Juliano Pörsch ${ }^{1}$ \\ Catia Grisa ${ }^{2}$ \\ Rumi Regina Kubo ${ }^{3}$
}

\begin{abstract}
RESUMO
Em 2013, o governo brasileiro inovou na política de Assistência Técnica e Extensão Rural (ATER). Pela primeira vez foi realizada uma chamada pública de ATER destinada especificamente a povos indígenas, sendo que a mesma abrangeu, no Rio Grande do Sul, as terras indígenas do Guarita, Ligeiro e Cacique Doble, além do acampamento de Passo Grande do Forquilha. Este artigo visa analisar os elementos que confluíram para a emergência desta ação, reconstituindo os fatores (ou fluxos) que permearam a trajetória de construção da chamada pública de ATER Indígena. Para tanto, foram realizadas entrevistas semiestruturadas a mediadores em nível local/regional, estadual e nacional, além de pesquisas bibliográfica e documental. Partindo das contribuições do modelo dos múltiplos fluxos, de John Kingdon, observou-se nesse processo a importância do Território da Cidadania Noroeste Colonial, da dependência de trajetória, de mediadores sociais, do "clima político" nacional e do protagonismo indígena na definição desta agenda e na luta indígena por reconhecimento.
\end{abstract}

Palavras-chave: ATER indígena, modelo dos múltiplos fluxos, políticas públicas, reconhecimento.

\section{PATH TO THE CONSTRUCTION OF PUBLIC CALL OF TECHNICAL ASSISTANCE AND RURAL EXTENSION FOR INDIGENOUS}

\begin{abstract}
In 2013, the Brazilian Government innovated in the policy of technical assistance and rural extension. For the first time, a Public Call was made specifically for indigenous peoples, and in Rio Grande do Sul, the indigenous lands of Guarita, Ligeiro and Cacique Doble, as well as the Passo Grande do Forquilha encampment. This article

\footnotetext{
1 Graduado em Tecnologia em Desenvolvimento Rural (UFRGS). Mestrado em Desenvolvimento Rural (UFRGS). E-mail: juliano.porsch@gmail.com

${ }^{2}$ Graduada em Agronomia (UFPEL). Mestrado em Desenvolvimento Rural (UFRGS). Doutorado em Ciências Sociais (UFRRJ). Professora do Departamento Interdisciplinar e do Programa de Pós-Graduação em Desenvolvimento Rural (UFRGS). E-mail: catiagrisaufrgs@gmail.com

${ }^{3}$ Graduada em Ciências Biológicas (UFGRS) e Artes Plásticas (UFRGS). Mestrado em Botânica (UFRGS). Doutorado em Antropologia Social (UFRGS). Professora do Departamento de Ciências Econômicas e Relações Internacionais e do Programa de Pós-Graduação em Desenvolvimento Rural (UFRGS). E-mail: rumikubo2002@gmail.com
} 
aims at analyzing the elements that came together for the emergence of this action, reconstituting the factors (or streams) that permeated the path of construction of the Public Call of technical assistance and rural extension for indigenous. For this, we conducted semi-structured interviews with mediators at the local / regional, state and national levels, as well as bibliographical and documentary research. Based on the contributions of John Kingdon's Multiple Streams Model, we note in this process the importance of the Território da Cidadania Noroeste Colonial, its Path dependence, of social mediators, the national "political climate" and indigenous protagonism in the definition of this indigenous struggle for recognition.

Key-words: multiple streams model, public policies, recognition, technical assistance and rural extension for indigenous.

\section{INTRODUÇÃO}

O presente artigo pretende discutir a trajetória da construção da Chamada Pública de ATER Indígena, com ênfase na Chamada no 001/2013 do Ministério do Desenvolvimento Agrário (MDA). O trabalho tem como objetivo analisar os elementos que confluíram para a emergência desta ação, reconstituindo os fatores (ou fluxos) que permearam a trajetória de construção da chamada pública de ATER Indígena. Esta chamada pública ${ }^{4}$, realizada no âmbito do Programa Brasil Sem Miséria, foi a primeira destinada especificamente a povos indígenas no país e abrangeu, no Rio Grande do Sul, as Terras Indígenas (TI) do Guarita, Ligeiro e Cacique Doble, além do acampamento de Passo Grande do Forquilha ${ }^{5}$.

Visando atender ao objetivo proposto, foi feito levantamento bibliográfico, pesquisas documental e de campo. O levantamento bibliográfico objetivou verificar o "estado da arte" sobre políticas públicas, os indígenas da etnia Kaingang e a Terra Indígena do Guarita. A pesquisa documental baseou-se no acesso a informações da Fundação Nacional do Índio (FUNAI), do Ministério do Desenvolvimento Agrário, do Ministério do Desenvolvimento Social (MDS) e da EMATER/RS-Ascar (EMATER/RS).

Para execução da pesquisa de campo, foram entrevistados mediadores em nível local/regional, a representante da comunidade indígena no Colegiado de Desenvolvimento Territorial (Codeter) ${ }^{6}$, o ex-articulador do Território da Cidadania Noroeste Colonial (TCNC), e o ex-assessor do TCNC. Em nível estadual, foram entrevistados o ex-delegado da Delegacia Federal do Desenvolvimento Agrário/RS e a coordenadora estadual da EMATER/RS-Ascar para a ATER Indígena. Em nível nacional, foram realizadas entrevistas com o gestor da Secretaria Especial de

\footnotetext{
${ }^{4}$ A Lei de ATER (Lei no 12.188, de 11 de janeiro de 2010), desvinculou a contratação dos serviços de ATER da Lei de Licitações (Lei de ํo 8.666 de 21 de junho de 1993), dispensando as licitações e substituindo este processo para contratação de instituições públicas ou privadas de ATER através da modalidade de Chamadas Públicas, simplificando o processo de comprovação e pagamento dos serviços, que passaram a ser feitos por meio de atestes (assinaturas) dos beneficiários, bem como propiciou focalizar o objeto a ser contratado, o público atendido e a área geográfica a ser atendida, facilitando o atendimento a públicos específicos.

${ }^{5}$ A TI Guarita se localiza nos municípios de Tenente Portela, Redentora e Erval Seco; a TI Ligeiro, está localizada no município de Charrua; a TI Cacique Doble e o acampamento Passo Grande do Forquilha estão localizados no município de Cacique Doble.

${ }^{6}$ Nos Colegiados de Desenvolvimento Territorial (Codeter) eram discutidos e construídos os projetos de desenvolvimento para o território, nos quais participavam representantes das três esferas de governo e da sociedade, sendo que cada território possuía seu Colegiado.
} 
Agricultura Familiar e Desenvolvimento Agrário (SEAD), com gestor da Coordenação Geral de Promoção ao Etnodesenvolvimento CGETNO/FUNAl e gestor do Ministério do Desenvolvimento Social e Agrário (MDSA). O critério para a escolha destes entrevistados relaciona-se aos papeis de representantes institucionais assumidos por estes, mas também foi reforçado pelas indicações ao longo das entrevistas, em que eram reiterados como atores-chaves no processo em questão. Utilizou-se um roteiro semiestruturado, acompanhado de diálogo aberto com o entrevistado, que visava indagar como este percebeu a construção desta política pública, os principais atores envolvidos no processo e outras considerações pertinentes ao tema da pesquisa. As entrevistas foram realizadas entre novembro de 2016 e março de 2017.

Para a análise foi utilizado o Modelo dos Múltiplos Fluxos (Multiple Streams Model) ${ }^{7}$ de Kingdon, que possibilita evidenciar o processo de formulação de políticas (e/ou instrumentos das políticas) e a mudança na agenda governamental, destacando a dinâmica das ideias no processo. Conforme comenta Capella (2006)

\begin{abstract}
Kingdon considera as políticas públicas como um conjunto formado por quatro processos: o estabelecimento de uma agenda de políticas públicas; a consideração das alternativas para a formulação de políticas públicas, a partir das quais as escolhas serão realizadas; a escolha dominante entre o conjunto de alternativas disponíveis e, finalmente, a implementação da decisão (CAPELLA, 2006, p.25).
\end{abstract}

Para Kingdon, um problema entra na agenda de política pública quando há a combinação de três fluxos - fluxo dos problemas (problem stream), fluxo político (political stream) e fluxo das soluções (policy stream) - juntamente com a abertura de uma janela de oportunidade (policy window). Para o autor, estes três fluxos decisórios seguem um curso de relativa independência e, em momentos críticos, eles convergem por meio da ação de empreendedores da política pública (policy entrepreneurs), desencadeando mudanças na agenda e colocando a política em cena. Nesta abordagem, é elementar a expressão "Acho que chegou a hora de considerar essa ideia!" Assim, pode-se dizer que a tônica apresentada neste estudo é: chegou a hora da chamada pública de ATER Indígena (CASADO, 2014; CAPELLA, 2006; KINGDON, 2006).

O artigo está estruturado em cinco subseções, sendo esta primeira introdutória ao tema e ao locus da pesquisa. A segunda abordará o fluxo dos problemas. Na terceira, trata-se do fluxo político da demanda e, na quarta, se apresentam as soluções para o problema, bem como a articulação dos fluxos e os empreendedores envolvidos. Por fim, são realizadas as considerações finais sobre este processo.

\title{
2. A POBREZA EXTREMA E A FALTA DE POLÍTICAS DE GERAÇÃO DE RENDA E SEGURANÇA ALIMENTAR PARA OS POVOS INDÍGENAS
}

Na análise do fluxo dos problemas, é importante analisar como as questões são reconhecidas como problemas públicos e como passam a ocupar a agenda do governo. Para Kindgon, em nosso cotidiano, vivenciam-se diversas problemáticas que não necessariamente chamam a atenção pública ou demandam ações, no

\footnotetext{
7 A abordagem do Modelo dos Múltiplos Fluxos propiciou a organização de ideias e a compreensão do processo de forma clara. No entanto, assim como efetuado neste trabalho, deve-se, quando necessário, abrir mão de determinada variável que está no modelo, mas que eventualmente não ocorra ou não é bem visível no caso concreto.
} 
entanto, estas mesmas situações podem passar a ser consideradas problemáticas quando governos ou formuladores de políticas percebem a necessidade de fazer algo sobre este determinado problema (KINGDON, 2006).

Nesse processo, indicadores, eventos, crises e feedback de ações podem ser os elementos catalisadores. Os indicadores podem apontar para a existência de uma questão, que poderá vir a ser percebida como problema pelos formuladores de políticas. Não necessariamente os indicadores por si só transformam questões em problemas, mas podem substancialmente serem utilizados para tal fim, demonstrando uma situação. Muitas vezes, um problema é constatado através de eventos de grande magnitude, como crises, desastres ou símbolos. Geralmente, não elevam um problema para agenda, mas reforçam a percepção de determinado assunto. Já os feedbacks de ações relacionam-se a informações referentes a como se comportaram ou estão se comportando outros programas ou políticas em desenvolvimento pelo governo. Como reitera Capella (2006),

\begin{abstract}
mesmo que indicadores, eventos, símbolos ou feedbacks sinalizem questões específicas, esses elementos não transformam as questões automaticamente em problemas. Essencial para o entendimento do modelo é necessário compreender que problemas são construções sociais, envolvendo interpretação (CAPELLA, 2006, p. 26).
\end{abstract}

Analisando o fluxo dos problemas, pode-se considerar a pobreza extrema, aliada à falta de políticas públicas efetivas de geração de renda e de segurança alimentar para os povos indígenas, como os elementos principais na constatação do problema.

Como indicadores que auxiliaram a dar visibilidade ao problema, cita-se a mortalidade ${ }^{8}$ e a exploração do trabalho infantil. Entre dezembro de 2000 e março de 2001, ocorreu a morte de 12 crianças na Terra Indígena do Guarita relacionadas com desnutrição e falta de saneamento. Este fato teve repercussão nacional e indicou a falta de políticas públicas relacionada à Segurança Alimentar e Nutricional das comunidades indígenas. Também há de se mencionar a matéria do Jornal Zero Hora de Porto Alegre, publicada no dia oito de agosto de 2000, sob o título "Índias prostituídas: corpo de menina é negociado em bailão", referente à prostituição de adolescentes indígenas na TI do Guarita (WAGNER, 2000). Embora a matéria não aborde por esta ótica, ela permite - de forma contundente e sensacionalista relacionar $\mathrm{o}$ fato à condição de miserabilidade à que a comunidade estava historicamente exposta (WAGNER, 2000, DESNUTRIÇÃO..., 2001; BARROS, 2001; MITCHEL, 2001).

A partir deste período, várias políticas públicas foram implementadas ou potencializadas em áreas indígenas no Rio Grandes do Sul, como redes de água, melhoria no atendimento médico pela Fundação Nacional de Saúde (FUNASA) posteriormente substituída pela Secretaria Especial de Saúde Indígena, SESAI; distribuição de cestas básicas, políticas de transferência de renda (Vale-gás, Bolsa Escola, Bolsa Família); eletrificação rural (Luz para Todos, em 2006), Programa Nacional de Habitação Rural, Programa Nacional de Alimentação Escolar, entre outros.

Todas estas políticas relacionam-se à diminuição da mortalidade infantil e à melhoria das condições de vida desta população. Apesar disto, restaram problemas

\footnotetext{
${ }^{8}$ Dados da FUNAI (2012a), baseados em informações do IBGE (2010), dão conta de que a mortalidade infantil até o primeiro ano de vida em populações indígenas é de 41,81 casos para cada mil nascidos vivos, muito superior à média nacional de 15,6/1000.
} 
sob um escopo mais abrangente e estruturante, como os relacionados à falta de renda e à insegurança alimentar e nutricional, exigindo políticas públicas de maior efetividade a estas carências.

Como feedbacks de ações, pode-se considerar as políticas públicas RS Rural ${ }^{9}$, Pronaf $\mathrm{B}^{10}$ e Carteira Indígena ${ }^{11}$, que não tiveram um acompanhamento satisfatório na implantação e na condução de recursos materiais e financeiros, fazendo com que a comunidade da TI Guarita encontrasse dificuldades para seu uso pleno. Referente ao RS Rural, contatou-se a ênfase na questão produtivista, descolado da realidade social e sem apoio técnico (SOMPRÉ, 2007; SOARES, 2010). No Pronaf B, conforme dados da Agência do Banco do Brasil de Tenente Portela, em torno de $90 \%$ das trezentas e cinquenta famílias tomadoras do crédito ficou inadimplente porque o recurso foi liberado após o período indicado para o plantio de soja e milho, além de não contar com assistência técnica. Quanto à Carteira Indígena, conforme relatório do Ministério do Meio Ambiente, houve falta de assistência técnica, demora na liberação dos recursos e baixo número de famílias beneficiadas, (MMA, 2007).

Como feedback positivo, menciona-se a aplicação da chamada pública de ATER Leite, no período de 2011 e 2012, destinada à agricultura familiar. Conquistada pelo Território da Cidadania Noroeste Colonial em 2010 e implementada pela EMATER/RS-Ascar, esta chamada atendeu quatro mil famílias neste território, com avaliações positivas por parte do MDA, fato que respaldou a ATER estadual. Apesar destes resultados positivos, ficou notável a exclusão da comunidade indígena, que não foi beneficiada neste processo, desencadeando a premência de ações específicas.

Todos estes elementos demonstraram a necessidade de colocar a ATER Indígena na agenda pública, tanto pela expectativa da comunidade indígena, quanto - e em especial - pelos tomadores de decisão no âmbito do Ministério do Desenvolvimento Agrário, conforme será apontado na sequência.

\section{ELEMENTOS POLÍTICOS A FAVOR DA QUESTÃO INDÍGENA}

Para Kingdon (2006, p. 229), "desdobramentos na esfera política são poderosos formadores de agenda", sendo que, nesta esfera, o consenso se dá de forma mais efetiva por meio da negociação, do que da persuasão. O fluxo político é composto de três elementos: a) sentimento ou "clima nacional": a atmosfera adequada a que determinada ideia esteja sendo compartilhada pelo maior número de pessoas em determinado período, o que influencia na promoção ou não desta determinada ideia; b) grupos de pressão: forças políticas organizadas no Congresso,

\footnotetext{
9 Programa de Manejo dos Recursos Naturais e de Combate à Pobreza Rural. Empréstimo celebrado entre o Estado do Rio Grande do Sul e o BIRD em 11 de julho de 1997. Visava o combate à pobreza rural, a degradação dos recursos naturais e ao êxodo da população rural do Estado, promovendo ações integradas de infraestrutura familiar e comunitária, geração de renda e manejo e conservação dos recursos naturais. Atendeu entre 1997 a 2005, agricultores familiares e agricultores assentados, pecuaristas familiares, pescadores profissionais artesanais, povos indígenas e comunidades remanescentes de quilombos.

${ }_{10} \mathrm{O}$ Programa Nacional de Fortalecimento da Agricultura Familiar possuía neste período 6 grupos para acesso aos recursos, conforme a renda ou situação fundiária, sendo os grupos A, A/C, B, C, D e E. No caso do Grupo B, a condição de acesso era renda familiar máxima anual de $R \$ 2.000,00$, excluídos benefícios previdenciários e, que no mínimo $30 \%$ da renda viesse da exploração agropecuária e não-agropecuária do estabelecimento. Era uma linha de microcrédito para combate à pobreza rural, financiando até $\mathrm{R} \$ 1.000,00$ por família.

${ }_{11}$ A Carteira de Projetos Fome Zero e Desenvolvimento Sustentável em Comunidades Indígenas - Carteira Indígena, foi uma ação conjunta do Ministério do Meio Ambiente (MMA) e do Ministério do Desenvolvimento Social e Combate à Fome (MDS), com o objetivo de promoção do desenvolvimento sustentável e da segurança alimentar e nutricional entre os povos indígenas.
} 
movimentos sociais, sociedade civil organizada, imprensa, entre outros, pautando a problemática; c) eventos internos ao governo: mudanças de pessoas em posições estratégicas, mudanças de gestão, ou mudança de setor competente, que favorecem a entrada do tema na agenda. "O início de um governo é o momento mais propício para mudanças na agenda" (CAPELLA, 2006, p. 29).

Por este fluxo, pode-se analisar alguns condicionantes que facilitaram a entrada do tema da ATER Indígena na agenda. O primeiro Governo de Dilma Rousseff (2011-2014), com o slogan "País Rico é País sem Pobreza", se propôs a ser um governo de continuidade aos Governos de Luiz Inácio Lula da Silva (20032006 e 2007-2010), ao menos no que diz respeito à melhoria na distribuição de renda e no combate à pobreza extrema. O lançamento do Plano Brasil Sem Miséria (PBSM), em junho de 2011, instaurou um novo patamar institucional na condução de políticas públicas que visavam o enfrentamento à pobreza e à extrema pobreza no país, com uma série de ações articuladas em nível federativo para obtenção de seus objetivos. Com coordenação do MDS, mas envolvendo vinte e dois Ministérios, o Plano envolveu mais de cem ações, programas ou políticas distribuídas em três eixos: garantia de renda, inclusão produtiva e acesso a serviços (SAMBORSKI, 2016; PACÍFICO, 2017). Dentre eles, destacava-se a ATER, com a finalidade de contribuir para a inclusão produtiva.

A criação da Política Nacional de Gestão Territorial e Ambiental de Terras Indígenas (PNGATI) em 2012, também se insere neste contexto, por ser uma política que se balizou pela participação dos povos indígenas em suas etapas de construção. Esta política indigenista foi construída a partir da perspectiva de relações interétnicas proposta por Roberto Cardoso de Oliveira, que enfatiza as relações simétricas e democráticas entre Estado e povos indígenas. Os precedentes para essa construção foram os aprendizados e experiências acumuladas no Programa PPG7 ${ }^{12}$, por meio do PDPI ${ }^{13}$ e PPTAL ${ }^{14}$ e no Projeto GATI ${ }^{15}$. Também contribuiu neste processo a criação de Grupo de Trabalho Interministerial (GTI), em 2008, que reuniu de forma paritária técnicos do Ministério da Justiça e do Ministério do Meio Ambiente, representantes dos povos indígenas de todas as regiões do Brasil e representantes de organizações da sociedade civil, com a finalidade de elaborar uma proposta de Política Nacional de Gestão Territorial e Ambiental de Terras Indígenas (CARDOSO DE OLIVEIRA, 2000; PRINTES et al, 2012).

Dentro deste "clima político" nacional favorável à questão indígena, também se insere o cenário estadual gaúcho, com o governo de Tarso Genro (2011-2014), que, entre outras ações, ampliou significativamente o orçamento do Estado para a extensão rural, ampliando o quadro de pessoal da EMATER/RS-Ascar e potencializando $\mathrm{o}$ atendimento aos públicos vulnerabilizados. Confluente e complementar ao PBSM, o governo do Estado também criou o Programa RS Mais Igual, política estadual de transferência de renda, complementar às ações do Plano Brasil Sem Miséria.

Aproveitando o cenário favorável e contribuindo para a realização do mesmo, diversos grupos de pressão tiveram importância na definição da agenda da ATER Indígena:

\footnotetext{
12 Programa Piloto para a Proteção das Florestas Tropicais do Brasil (PPG7), proposto pelo grupo dos sete países mais ricos do mundo (G7), em 1991.

${ }_{13}$ Projetos Demonstrativos dos Povos Indígenas, subprojeto do PPG7.

14 Projeto integrado de Proteção às Populações e às Terras Indígenas, subprojeto do PPG7.

15 Projeto Gestão Ambiental e Territorial Indígena, o qual é fruto de realização conjunta entre o movimento indígena brasileiro, Fundação Nacional do Índio (FUNAI), Ministério do Meio Ambiente (MMA), The Nature Conservancy (TNC), Programa das Nações Unidas para o Desenvolvimento (PNUD) e Fundo Mundial para o Meio Ambiente (GEF-Global Environment Facility).
} 
a) Território da Cidadania Noroeste Colonial (RS)

O Território da Cidadania ${ }^{16}$ Noroeste Colonial, criado em outubro de 2007 e constituído em março de 2009, foi composto por trinta e quatro municípios, envolvendo os Conselhos Regionais de Desenvolvimento (COREDE's) ${ }^{17}$ Celeiro e Noroeste Colonial, além dos municípios de Cruz Alta e Boa Vista do Cadeado (ALLEBRANDT et al., 2012). Para Allebrandt et al. (2012, p. 9), "uma das justificativas para a criação do Território Noroeste Colonial foi a existência das duas aldeias indígenas" na região, sendo que elas encontraram espaços de diálogo e de participação nesta nova instância de planejamento territorial. Elementos emblemáticos neste sentido foram o estabelecimento da Setorial Indígena e a construção do Plano de Desenvolvimento Territorial Indígena (em 2010), a fim de discutir as demandas das comunidades indígenas e incluí-las na pauta de reivindicações. Neste plano, foram definidas atividades e áreas prioritárias, como "Água para Todos" na área de Saúde, e "ATER para Todos" na área da Agricultura. Como primeiro resultado destas demandas, foi construído na comunidade do Km-10, na TI Guarita, um Centro Comunitário para a etnia Kaingang para a realização de festas comunitárias e de reuniões semanais entre as lideranças indígenas.

Neste contexto, verifica-se que a participação indígena se dá não só pela receptividade encontrada no Colegiado, como porque

há no programa uma representação maior das instituições e classes que não têm muita participação decisória em outras instâncias. "Quanto menos possibilidade de participação desses cidadãos parece que tem mais participação dentro do Território, então nesse sentido o TC atende os seus objetivos". Assim, o entrevistado explica que essas classes menos vistas pelos diferentes setores governamentais acabaram encontrando no programa um espaço de participação (DECKERT, 2017, p. 422).

A análise acima ganha importância considerando que, até então, a discussão e o planejamento regional ocorriam no âmbito dos COREDE's, sendo a participação nestes limitada a prefeitos, secretários municipais, instituições governamentais e algumas entidades da sociedade civil (DECKERT, 2017).

Neste sentido, entende-se que o Território da Cidadania foi um dos principais grupos de pressão, bem como um local onde frutificaram as discussões para a construção da ATER Indígena. Para o ex-delegado do MDA no RS, a política territorial contribuiu para que a chamada pública tomasse corpo e fosse canalizada a seu destino,

Para chegar nesta conquista dos indígenas, nós tivemos antes esta grande conquista [política territorial]. Aquele Território foi conquistado, foi a demanda apresentada ao MDA, nós fizemos os estudos (...), o recorte dos municípios, indicadores e tal. Porque tem que ser submetido ao Condraf. (...). Isso foi feito e

\footnotetext{
${ }^{16}$ Programa Territórios da Cidadania (PTC) criado pelo Decreto não numerado de 25 de fevereiro de 2008, visava garantir que o desenvolvimento envolvesse diversas dimensões, como econômica, sociocultural, político institucional e ambiental. Foi uma política coordenada pela Secretaria de Desenvolvimento Territorial do Ministério do Desenvolvimento Agrário (SDT/MDA), mas que abrangia políticas públicas de diversos ministérios destinadas principalmente a atender os territórios com mais baixos níveis de IDH (Índice de Desenvolvimento Humano), enfrentando a pobreza e a miséria rural.

17 Os Conselhos Regionais de Desenvolvimento (Coredes) são regiões de planejamento criadas em 1994, objetivando a promoção do desenvolvimento regional. Atualmente, essa divisão conta com vinte e oito regiões.
} 
foi construído o Território (Entrevistado DFDA/RS, Dados da pesquisa).

\title{
b) Organização indígena
}

Outro grupo de pressão foi a própria comunidade indígena, que cobrava dos entes federativos sua inclusão em políticas públicas específicas. Esta pressão se dava por meio de diálogos diretos das lideranças indígenas (cacicado) com agentes políticos, da participação de representantes da comunidade no Colegiado Territorial, e da participação da população da Terra Indígena no Processo de Participação Popular e Cidadã (PPC - processo de descentralização do orçamento do governo do estado do RS $)^{18}$. Estes múltiplos mecanismos de diálogo e pressão política propiciaram reconhecimento de suas demandas e da necessidade de efetivação das mesmas. Segundo a antropóloga da EMATER/RS e coordenadora estadual da Chamada de ATER Indígena,

Eu entendo que o protagonismo da Chamada do Rio Grande do Sul foi dos próprios indígenas, no sentido de que já havia um movimento ali, com outras entidades a nível local, da região Celeiro (...), principalmente do Guarita e do Inhacorá, que atuam muito junto as lideranças, de estar ocupando, e já na época já ter acionado outras políticas do MDA no ambiente do Território (da Cidadania). Então, pelo relato do [nome de uma pessoa], que foi nosso colega e delegado na época, do MDA, ele disse que aquilo bateu muito forte no MDA local, na Delegacia Federal (DFDA/RS), (...) de que os índios mais uma vez tinham que se adaptar à política da agricultura familiar e nesse sentido, não vinha nada... e eles ocupavam o espaço, eles estavam participando (Antropóloga da EMATER/RS, Dados da pesquisa).

A antropóloga ainda ressalta o envolvimento indígena na implementação da Chamada de ATER,

\begin{abstract}
e depois, quando saiu o edital, (...) seguiu o protagonismo dos indígenas no sentido de que realmente visualizaram qual a entidade que poderia apresentar uma proposta, pra ela não ser deserta e, pressionaram digamos assim, a diretoria da EMATER, a regional ljuí, para que efetivamente a EMATER se organizasse para apresentação de uma proposta técnica válida (Antropóloga da EMATER/RS, Dados da pesquisa).
\end{abstract}

Todo este movimento, em torno das formas pelas quais se dão os processos de reconhecimento, segundo Honneth, inscrevem-se no processo contemporâneo de luta por reconhecimento. Este filósofo alemão, em um de seus principais trabalhos - Luta por reconhecimento: a gramática moral dos conflitos sociais - tenta mostrar como indivíduos e grupos sociais se inserem na sociedade atual. Para ele, isso ocorre hoje através de uma luta por reconhecimento intersubjetivo e não por autoconservação, como diziam Nicolau Maquiavel e Thomas

\footnotetext{
${ }^{18}$ Através da mobilização da comunidade indígena em votações do PPC, nos anos de 2011, 2012 e 2013 houve aportes de recursos para projetos de segurança alimentar e inclusão produtiva, que no primeiro contemplou apenas sementes de milho, feijão e abóboras e nos seguintes ampliou para equipamentos de agricultura e artesanato, pequenas criações, mudas frutíferas e sementes através da Secretaria de Estado do Desenvolvimento Rural, Pesca e Cooperativismo (SDR).
} 
Hobbes. Para Honneth, as três formas de reconhecimento são: o amor, o direito e a solidariedade. Os indivíduos e os grupos sociais, somente formam a sua identidade, se forem reconhecidos intersubjetivamente (HONNETH, 2003).

Neste sentido, observa-se que o fato das comunidades indígenas Kaingang inseridas no Território da Cidadania Noroeste Colonial não terem sido beneficiárias da ATER através da chamada pública de ATER Leite no ano de 2010 (que naquele momento foram excluídas da política pública que era destinada apenas a agricultores familiares) criou grande frustração, gerando um fator desencadeador de uma luta por reconhecimento destas comunidades, diante do estigma, do preconceito e da desvalorização deste grupo étnico.

\section{c) EMATER/RS-Ascar}

Mesmo sendo uma entidade que presta serviço público, entende-se a EMATER/RS como formadora de pressão na definição da agenda social, principalmente em função da cobrança existente a ela pela comunidade indígena e pelos próprios técnicos, por estar sendo a gestora dos recursos do governo estadual nos projetos de segurança alimentar e, de certa forma, por ser uma entidade com Certificado de Entidade Beneficente de Assistência Social - CEBAS ${ }^{19}$.

Logra saber também que a EMATER/RS possuía relação muito próxima com o MDA, tanto pelas atividades desenvolvidas entre ambos, quanto pela burocracia cedida pela EMATER/RS ao Ministério em vários cargos com poder de decisão. ${ }^{20}$ Ademais, nota-se uma forte influência gaúcha no comando do Ministério, visto que foram Ministros do Desenvolvimento Agrário, os gaúchos Miguel Rosseto (1\%/01/2003 a 31/03/2006), Guilherme Cassel (03/04/2006 a 31/12/2010), Pepe Vargas (14/03/2012 a 17/03/2014) e novamente Miguel Rosseto (17/03/2014 a 08/09/2014), sendo substituído interinamente pelo secretário-executivo Laudemir Müller, até 31/12/2014. Estas relações favoreceram para que as demandas e reivindicações das comunidades indígenas circulassem da Terra Indígena do Guarita aos governos do Estado e da Federação.

Para além do cenário político favorável e da atuação dos grupos de pressão, três eventos específicos também contribuíram para colocar a questão indígena em pauta, sendo eles: a criação da Sala de Situação do PBSM, a emissão de Informações Técnicas da FUNAI e o Acordo de Cooperação Técnica entre MDA, MDS, SDR e EMATER.

\section{i) Sala de Situação}

Com o advento do Plano Brasil Sem Miséria, em junho de 2011, as ações previstas eram tratadas através da atuação de três instâncias decisórias e

\footnotetext{
${ }^{19}$ A certificação, concedida às organizações da assistência social, é um instrumento que possibilita usufruir da isenção das contribuições sociais, tais como a parte patronal da contribuição previdenciária sobre a folha de pagamento, Contribuição Social sobre o Lucro Líquido - CSLL, Contribuição para o Financiamento da Seguridade Social - COFINS e Contribuição PIS/PASEP, permite ainda a priorização na celebração de contratualização/convênios com o poder público, entre outros benefícios.

${ }^{20}$ Citamos, como exemplo três trabalhadores cedidos pela EMATER/RS ao MDA: 1) no cargo de delegado, na Delegacia Federal de Desenvolvimento Agrário, em Porto Alegre, no período de 08/2004 a 07/2012, sendo que este, após ocupou o cargo de assessor do ministro em Brasília, no período de 08/2012 a 03/2013 e entre 03/2013 a 04/2014 o cargo de diretor do Departamento de Geração de Renda no mesmo ministério; 2) no cargo de Diretor Substituto do Departamento de Assistência Técnica e Extensão Rural (DATER) e Coordenador Geral de ATER e Educação, no mesmo Departamento da Secretaria da Agricultura Familiar, do Ministério do Desenvolvimento Agrário, de 2003 a 2010; 3) no cargo de Diretor do Departamento de Financiamento e Proteção à Produção, de 2002 a 2016.
} 
gerenciais: o Comitê Gestor, o Grupo Interministerial de Acompanhamento (GIA $)^{21}$ e as Salas de Situação. Estas últimas eram formadas por representantes das áreas técnicas e decisórias dos Ministérios. Elas tinham a responsabilidade pela gestão e tratamento das informações para subsídio das decisões tomadas no âmbito do GIA e do Comitê Gestor. Haviam várias Salas, divididas por áreas temáticas, entre elas a dos Povos e Comunidades Tradicionais (MELLO, 2016).

A sala de situação é citada por todos os entes da esfera federal entrevistados (MDA, MDS, FUNAI e DFDA/MDA), demonstrando a importância estratégica que possuía na definição das decisões e na circulação das informações entre as instituições envolvidas.

\section{ii) Informação Técnica (IT) FUNAI}

Em 17 de julho de 2012, por solicitação da Sala de Situação do Programa de Fomento às Atividades Produtivas Rurais do MDS, a Coordenação Geral de Promoção ao Etnodesenvolvimento (CGETNO) da FUNAI emite a Informação Técnica № 094/CGETNO/2012 que subsidia o MDS e o MDA com informações e caracterização do público indígena para inserção no PBSM através do Programa Fomento e de chamada pública de ATER. A escolha das áreas a serem atendidas foi acordada entre a FUNAI, o MDS e o MDA e "considerou inicialmente, áreas indígenas inseridas nos quarenta e um municípios com maior número absoluto de indígenas extremamente pobres no meio rural (...), e a facilidade de logística para a implementação do Programa". Posteriormente, definiu-se que a escolha de doze mil famílias deveria estar focada, no âmbito dos quarenta e um municípios, as áreas dos dezesseis Distritos Sanitários Especiais Indígenas (DSEl's) definidos como prioritários no Plano Emergencial de Saúde e SAN Indígenas, visto que, estes apresentavam o maior número absoluto de mortalidade infantil evitável em 2011.

Neste processo, a Coordenação Regional da FUNAI de Passo Fundo e o Distrito Sanitário Especial Indígena (DSEl/Sesai) Interior Sul indicaram os municípios de Cacique Doble, Charrua, Redentora, Tenente Portela e Erval Seco para serem incluídos na chamada pública, contemplando as Terras Indígenas Cacique Doble, Ligeiro, Guarita e do acampamento Passo Grande do Rio Forquilha (abrangendo as etnias kaingang e guarani).

Em 19 de setembro do mesmo ano, a CGETNO emite a Informação Técnica № 131/CGETNO/2012, por solicitação da SESAN/MDS, que "atualiza e complementa a IT 094/CGETNO, (...) com o objetivo de subsidiar manifestação da FUNAI junto ao MDS, quanto à oportunidade e pertinência do atendimento a 12 mil famílias (...), ainda em 2012". Nela, se reafirma que "a decisão quanto ao número de famílias a serem incluídas em 2012, 12 mil, foi tomada na Sala de Situação do PBSM, considerando a meta específica para povos e comunidades tradicionais, de $15 \%$ da meta global (...)". Menciona também as orientações da Comissão Nacional de Política Indigenista, da I Conferência Nacional de ATER (2012) e da PNGATI.

Sobre o "Potencial de acesso da Chamada por entidades de ATER", a IT destaca que "as instituições de ATER de todos os estados incluídos na Chamada, em maior ou menor medida, já desenvolvem ou desenvolveram experiências de

\footnotetext{
${ }^{21} \mathrm{O}$ Comitê Gestor era formado pelos ministros e ministras dos Ministérios do Desenvolvimento Social, da Fazenda, do Planejamento e da Casa Civil, tendo como responsabilidade coordenar as ações para implementação e execução das ações previstas. O Grupo Interministerial de Acompanhamento era formado por representantes de todos os ministérios envolvidos no PBSM, tendo como função a consolidação de ações, estabelecimento de metas e acompanhamento dos resultados de implementação e execução.
} 
trabalho junto aos Povos Indígenas na temática do desenvolvimento rural sustentável(...)”, (FUNAI, 2012b, p.7). Sobre o Rio Grande do Sul comenta,

a EMATER tem experiência e tradição de apoio aos povos indígenas, tendo desenvolvido políticas específicas de desenvolvimento rural sustentável, a exemplo do "Rio Grande do Sul Rural - RS Rural" (entre 1999-2002, durante o Governo de Olívio Dutra). Atualmente, o estado está bastante engajado no combate à extrema pobreza, tendo criado o "RS mais Igual", que dialoga diretamente com o PBSM. (...). Além disso, o estado possui um Conselho Estadual dos Povos Indígenas (FUNAI, 2012b, p. 7).

Concluindo o documento, a CGETNO afirma ser "pertinente e desejável" que se atenda todas as doze mil famílias nas áreas selecionadas para a chamada pública, mas considera que, devido a diversos desafios e dificuldades, "a FUNAI deva se posicionar junto ao MDS, quanto à oportunidade e pertinência do atendimento à 12 mil famílias no âmbito chamada pública do Plano Brasil sem Miséria - PBSM, como segue:" (FUNAI, 2012b, p.20).

Indicar para a Chamada de 2012, o atendimento aos dois lotes referentes aos estados do Mato Grosso e do Rio Grande do Sul, que perfazem 3.000 famílias, nos quais há maior possibilidade imediata de êxito (FUNAl, 2012b, p. 21).

Estes dois documentos da FUNAI, com informações apuradas sobre população, perfil produtivo, desafios, estratégias, potencialidades e dinâmicas dos povos e terras indígenas que compunham as doze mil famílias com previsão de atendimento em todo o país, é reconhecido pelos informantes do MDA e MDS como documento fundamental para convencimento na tomada de decisão por parte da Sala de Situação do PBSM.

\section{iii) Acordo de cooperação MDA, MDS, SDR, EMATER}

Outro acontecimento de relevância foi a assinatura de Acordo de Cooperação celebrado entre a União (por intermédio do MDA e do MDS), o Estado do Rio Grande do Sul (por meio da Secretaria do Desenvolvimento Rural, Pesca e Cooperativismo) e a Associação Riograndense de Empreendimentos de Assistência Técnica e Extensão Rural (EMATER/RS). Este acordo, assinado em 12/07/2012 e publicado no Diário Oficial da União em 26/07/2012, tinha por objetivo "a articulação institucional para a execução de ações de inclusão produtiva rural que compõem o Plano Brasil Sem Miséria para famílias de agricultores e agricultoras familiares em situação de extrema pobreza".

Proposto principalmente devido à grande estiagem ocorrida no Rio Grande do Sul em 2012, este Acordo possibilitou a disponibilização pelo MDS do Programa de Fomento 22 a seis mil famílias de agricultores familiares, além do atendimento com serviços de ATER, com prazo de duração de vinte e quatro meses. Definia as

\footnotetext{
22 Instituído pela Lei n. 12.512 de 14 de outubro de 2011 e regulamentado pelo Decreto n. 7.644 de 16 de dezembro de 2011, criado para atender a população rural em situação de extrema pobreza e abrangidas pela Lei da Agricultura Familiar, para estimular a geração de trabalho e renda, melhorar a segurança alimentar e nutricional, incentivar a participação em ações de capacitação e incentivar a organização de seus beneficiários. A tônica deste instrumento era o acesso das famílias beneficiadas a um recurso nãoreembolsável de $\mathrm{R} \$ 2.400,00$ e acesso a assistência técnica e extensão rural.
} 
responsabilidades de cada ente envolvido, deixando implícito a necessidade de articulação dos entes para a consecução dos objetivos previstos. Em 18/07/2013, foi assinado Termo Aditivo ao Acordo, com publicação no DOU em 04/09/2013, alterando a Cláusula Terceira - Das Responsabilidades, que basicamente aumentava o número de famílias atendidas no estado, de seis mil para onze mil, bem como prorrogava o Acordo para vinte e quatro meses a partir da data de assinatura deste aditivo.

Este acordo reforçou o compromisso institucional da EMATER/RS-Ascar em promover ações de extensão rural aos públicos em vulnerabilidade social, no entanto, na primeira etapa, novamente o público indígena estava alijado do processo.

\title{
4. AS "SOLUÇÕES" NA CONSTRUÇÃO DA ATER INDÍGENA
}

Conforme Kingdon (1995, p. 232), "a melhor forma de entender o surgimento de alternativas para políticas públicas é vê-lo como um processo de seleção, análogo ao processo de seleção natural", o qual o autor chama de "policy primeval soup" (sopa política primeva). "Inicialmente muitas ideias surgem desordenadamente, chocando-se umas com as outras, gerando novas ideias e formando combinações e recombinações. As origens de uma política podem parecer um pouco obscuras, difíceis de prever, entender ou estruturar". (KINGDON, 2006, p.232). No entanto, para Kingdon (2006), o processo de seleção entre as possíveis alternativas é mais visível que aquele de definição de suas origens. A utilização de critérios e padrões dão maior organicidade à política pública, sendo estes relacionados com a viabilidade técnica, a aceitação pela comunidade e a existência de custos toleráveis.

Analisando o Fluxo das Soluções para o caso empírico do presente trabalho, pode-se constatar como algumas alternativas se apresentaram e se constituíram para que houvesse a construção desta política. Assim, uma das alternativas foi o que Pierson (2000) intitula Path dependence ou dependência de trajetória, aliados a ideia de retornos crescentes ou feedbacks positivos. Para Pierson,

\begin{abstract}
Essa concepção de dependência da trajetória na qual as etapas anteriores em uma determinada direção induzem ainda mais movimento na mesma direção, é bem capturado pela ideia de retornos crescentes. Em processos de retornos crescentes, a probabilidade de novos passos na mesma trajetória aumenta a cada passo dado nessa trajetória. Isto ocorre porque os benefícios relativos da ação atual comparados às opções anteriormente possíveis aumentam com o tempo (PIERSON, 2000, p. 340).
\end{abstract}

Neste sentido, considera-se como inerentes a este processo de construção da política chamada pública de ATER Indígena os seguintes instrumentos legais: Lei $n^{\circ} 11.326$ de 24 de julho de 2006, "Lei da Agricultura Familiar"; Lei $n^{\circ} 12.188$ de 11 de janeiro de 2010, Lei de ATER e o Decreto no 7.215 de 15 de junho de 2010, que a regulamenta. Pode-se arguir que a existência deste aparato legal e institucional fortaleceu a sequência de tomadas de decisão no mesmo sentido.

Segundo o ex-delegado do MDA no RS, nas discussões no Território da Cidadania Noroeste Colonial observou-se que "não tinha nenhuma política (...) nenhuma política para os indígenas... que se adequasse a eles". Desta forma, existia certo constrangimento por parte do poder público em não conseguir 
apresentar à comunidade indígena propostas de melhoria às suas necessidades. $\mathrm{O}$ ex-delegado ainda reflete,

não tinha nada para indígenas, moral da história... não tinha mesmo. E a gente com a conversa: Isso tem que ser construído, eu não estava enrolando aquela gente, eu estava dizendo a história (Entrevistado DFDA/RS, Dados da pesquisa).

Assim, ficava a inquietação de não haver ainda ferramentas para o pronto atendimento às solicitações da comunidade indígena da região Noroeste do RS, como expressado pelo ex-delegado da DFDA/RS, referindo-se aos questionamentos de liderança indígena, representante Kaingang no Codeter,

o território estava constituído, tinha o seu plano, mas a oferta de políticas públicas não contemplava essa gente... Vamos construir! $\mathrm{E}$ a dona [nome de representante indígena]: Mas é sempre assim, para nós tem que construir. Não com estas palavras que estou te falando, mas era a mensagem dela: Não está claro que nós somos os mais necessitados, e não é o objetivo, já que é um Território da Cidadania (...), e nós não vamos ter (...). Aí eu disse para ela: Olha a senhora tem razão (...), mais uma vez vocês não estão sendo atendidos, mas o que eu posso fazer é apresentar essa demanda, conversar com os setores encarregados no MDA (...) foi o que eu fiz. Fiz contato com o [nome de gestor que atuava no DATER] (Entrevistado DFDA/RS, Dados da pesquisa).

Na sequência, conforme indicado pelo diretor do DATER, a demanda foi encaminhada para a Coordenadoria Geral de Povos e Comunidades Tradicionais (CGPCT/MDA), para que esta Coordenadoria apresentasse as especificidades necessárias para a Chamada, como local, público, recursos necessários, entre outros, visto que a ATER era uma opção com possibilidade de atendimento e com forte atuação e importância dentro do MDA, conforme relata o ex-delegado,

foi para eles (CGPCT), para eles verem isso (especificações da chamada), acho que foi em 2010. Em 2010, conquistamos o Território e encaminhamos a demanda (...). Não tinha recurso aquele ano para fazer e tão pouco encaminhada naquele ano para fazer a chamada" (Entrevistado DFDA/RS, Dados da pesquisa).

Para o ex-delegado, a possibilidade real de haver entidades que pudessem atender aos requisitos de uma chamada para ATER Indígena foi um dos principais argumentos para a futura definição de um edital específico, pois

a proposta estava lá encaminhada, e o RS foi o único estado que apresentou a demanda e apresentou capacidade de execução. Nesse sentido, foi fundamental a participação da EMATER, porque (...) esse projeto não aconteceria para o Brasil inteiro, se o Rio Grande do Sul não tivesse permitido suficiente confiança no sucesso da empreitada (Entrevistado DFDA/RS, Dados da pesquisa). 
O entrevistado reforça ainda a preocupação que o MDA tinha em tentar garantir o sucesso dessas chamadas a fim de comprovar a eficácia do formato jurídico "chamada pública", que era um instrumento recente e necessitava lograr êxito.

Não era só a questão dos índios, mas a própria instituição 'chamada pública' estava dando seus primeiros passos e tinha que mostrar confiabilidade, até para se firmar. Não fosse isso, não existiria hoje (...) a Agência (Anater), ela nasce disso, (...) dessa forma de fazer (Entrevistado DFDA/RS, Dados da pesquisa).

Os dois relatos acima demonstram bem a preocupação com Chamadas em que as entidades proponentes pudessem dar conta da execução. E este receio é bastante plausível se forem consideradas as chamadas para atendimento aos povos indígenas lançadas pelo MDA e o baixo sucesso nas contratações, conforme demonstrado no Quadro 1:

Quadro 1 - Chamadas públicas de ATER Indígena no âmbito do MDA

\begin{tabular}{|l|l|l|ll|}
\hline Chamada & Lotes & Local & Resultado & \\
\hline $001 / 2013$ & 1 & $\begin{array}{l}\text { Mato Grosso } \\
\text { Rio Grande do Sul }\end{array}$ & $\begin{array}{l}\text { Republicada em 2014 } \\
\text { Contratada }\end{array}$ \\
\hline $003 / 2014$ & 2 & Amazonas & Não contratada & \\
\hline $004 / 2014$ & $1,2,3$ e 4 & Acre & Desertas & \\
\hline $007 / 2014$ & 1 e 2 & $\begin{array}{l}\text { Mato Grosso do } \\
\text { Sul }\end{array}$ & Desertas & \\
\hline $008 / 2014$ & 1 e 2 & Roraima & $\begin{array}{l}\text { Contratada e não } \\
\text { concluída }\end{array}$ & \\
\hline $009 / 2014$ & 1 & Alto Solimões & Deserta & \\
\hline $001 / 2015$ & 8 lotes & $\begin{array}{l}\text { Semiárido } \\
\text { Nordestino }\end{array}$ & 3 lotes contratados & \\
\hline
\end{tabular}

Fonte: MDA (2017) e informações da pesquisa.

Depois desse primeiro momento da construção da Chamada, baseada na demanda encaminhada pelo Território da Cidadania Noroeste Colonial à Delegacia Federal do Desenvolvimento Agrário/RS (e esta ao Dater/MDA e CGPCT/MDA), entra em cena um novo componente importante que foi o Programa Brasil Sem Miséria. Conforme apontado pelo entrevistado no CGPCT/MDA,

o governo, ainda em 2012, nos levantamentos que ele fez, ele percebeu que o público indígena e os povos e comunidades tradicionais estavam entre os principais grupos que compunham aquele público da extrema pobreza e, para mim, parece que foi a partir daí que eles (MDS) procuraram então a FUNAI e o MDA. E por meio do Brasil Sem Miséria, acreditavam que poderiam reduzir os índices de extrema pobreza, porque essa população indígena, quilombola também, mas indígena principalmente, concentravam esses índices de extrema pobreza e que poderiam diminuir com uma atuação específica, via Chamada, via Fomento. (...) usando para isso a estrutura do MDA e da FUNAI (Entrevistado MDA, Dados da pesquisa). 
Corrobora, neste sentido, a informação do entrevistado da CGETNO/FUNAI sobre a inclusão no Programa Fomento,

procuramos fazer o desenho de uma chamada em que não somente houvesse a ATER, porque tanto os indígenas, como a nossa percepção aqui da FUNAI, estavam apontando que só a ATER não era suficiente para enfrentar o problema. Precisava de um aporte de recursos, mínimo que fosse para poder dar um primeiro passo de estruturação dos sistemas produtivos dos agricultores indígenas. E a partir de uma reinvindicação deles mesmos, que ficou muito clara na Conferência de ATER Indígena que a gente realizou em 2012 e 2013, de que eles queriam pequenos projetos voltados mesmo para a família indígena, entendendo (...) tanto o conceito de família nuclear (...), como também de família extensa. Então, foi por reinvindicação dos próprios indígenas esse modelo do Fomento estar apoiado nas famílias (Entrevistado FUNAl, Dados da pesquisa).

Da mesma forma, o Coordenador-Geral de Apoio a Povos e Comunidades Tradicionais da Secretaria Nacional de Segurança Alimentar e Nutricional do MDS salienta:

A demanda já era antiga, vinda das instituições sociais locais, cobrando extensão rural. Mas também do próprio Ministério Público Federal que cobrava ações visando diminuir a vulnerabilidade social a que estes povos estavam submetidos e da FUNAI, através de seus apontamentos sobre a situação (Entrevistado MDS, Dados da Pesquisa).

Entendemos que a proposta de construção da chamada de ATER Indígena apresentava viabilidade técnica, tanto pela imperiosa necessidade do suprimento de carências afetas a estas comunidades indígenas (amplamente discorrida pelas Informações Técnicas 094 e 131/2012 da CGETNO/FUNAI), quanto pela possível presença de empresa de ATER disposta a concorrer no Edital, o que veio a se confirmar posteriormente. Neste sentido, como explica a antropóloga da EMATER/RS,

\begin{abstract}
aí, a partir desta batida na porta, então... e ainda nós não tínhamos... porque o edital não deixa claro que viria o dinheiro do Fomento, que aí o [nome de representante legal da EMATER] disse: Não, se não é colado com uma transferência de renda nós não vamos nos meter (na chamada). E aí que nós chamamos então o quadro que já trabalhava nos municípios envolvidos (...). Tá, vamos encarar? Não vamos? Quais são as nossas condicionantes? E até que a gente abriu a possibilidade da transferência daqueles que já estavam (na EMATER) e se sinalizou a necessidade da contratação (de técnicos) e da contratação dos técnicos indígenas (Antropóloga da EMATER/RS, Dados da pesquisa).
\end{abstract}

Como a política de ATER e o instrumento chamada pública já eram políticas consolidadas, os custos já estavam aceitos e internalizados pelos agentes públicos e sociedade. No entanto, a chamada pública de ATER Indígena traz elementos diferenciados que desencadearam a sua construção através da efetivação de: a) demandas locais: as demandas represadas das comunidades indígenas do 
Noroeste do Rio Grande do Sul encontraram uma arena para discussão dentro do Território da Cidadania Noroeste Colonial (mesmo que inicialmente as demandas acabassem não sendo atendidas, criaram ambiente para que estas fossem levadas ao conhecimento do MDA, através de sua Delegacia Federal); b) instâncias diversas: o envolvimento de diferentes agentes e instâncias na construção da política, como MDA, MDS e FUNAI, além do protagonismo indígena; c) aspectos específicos para a diversidade étnica: trouxe a necessidade de contratação de tradutores para determinados povos, propôs e privilegiou a contratação de técnicos indígenas, norteando 0 foco da atuação da ATER nos princípio do etnodesenvolvimento e propôs aumento de carga horária na atividade "Orientação para Qualificação da Produção e Acesso às Políticas Públicas", que em outras chamadas era de 8 horas e nesta passa para 16 horas, justamente para melhor inserir os povos indígenas no acesso a políticas públicas. Salientamos, ainda, a ênfase no respeito à autodeterminação e autonomia dos povos indígenas ${ }^{23}$, verificado, por exemplo, no respeito à organização sócio-política indígena e no diálogo interétnico.

Além disso, convém ressaltar que, como a luta do povo Kaingang das Terras Indígenas do Guarita e Inhacorá pela conquista da Chamada de ATER se inicia a partir de 2010, com a sua exclusão na Chamada ATER Leite, após efetivação da Chamada de ATER Indígena e do incremento do Programa Fomento, houve na Terra Indígena do Guarita uma facilidade de entendimento por ser uma conquista da comunidade, diferentemente das demais Terras Indígenas atendidas, onde a política chegou no formato top down, sem discussão prévia com o público beneficiário.

\section{AS JANELAS DE OPORTUNIDADES E OS EMPREENDEDORES DA CHAMADA DE ATER}

Seguindo o modelo proposto por Kingdon, quando condições propiciam a convergência dos três fluxos (fluxo dos problemas, fluxo político e fluxo das soluções), abre-se uma janela de oportunidade, momento propício para que os empreendedores de políticas atuem na definição da política pública (KINGDON, 2006).

Podemos neste trabalho considerar como Janelas de Oportunidade dois momentos em separado. O primeiro, a homologação do Território da Cidadania Noroeste Colonial, que possibilitou a participação da voz indígena na apresentação de seus problemas e suas demandas. O segundo momento, a criação do Programa Brasil Sem Miséria, que ampliou significativamente os recursos de ATER a populações vulnerabilizadas e possibilitou o aporte de recursos ao financiamento de projetos produtivos. Neste segundo momento, teve significativa importância a criação de Salas de Situação, onde empreendedores puderam fazer suas contribuições para escolha das áreas preferenciais.

Aproveitando estas janelas de oportunidades para avançar na institucionalização de ações para as comunidades indígenas, observamos a atuação de diversos empreendedores na construção da chamada pública de ATER Indígena.

\footnotetext{
23 DECLARAÇÃO DAS NAÇÕES UNIDAS SOBRE OS DIREITOS DOS POVOS INDÍGENAS. Nações Unidas 13 de setembro de 2007.

Artigo 3 - Os povos indígenas têm direito à livre determinação. Em virtude desse direito, determinam livremente a sua condição política e perseguem livremente seu desenvolvimento econômico, social e cultural. Artigo 4 - Os povos indígenas no exercício do seu direito à livre determinação, têm direito à autonomia ou ao autogoverno nas questões relacionadas com seus assuntos internos e locais, assim como os meios para financiar suas funções autônomas.
} 
Em nível local/regional, destaca-se a atuação do articulador e do assessor do Território da Cidadania Noroeste Colonial, que tiveram papel preponderante no acesso da comunidade indígena na arena de discussão e no encaminhamento de suas demandas. Ainda no Colegiado Territorial, salienta-se a atuação e a persistência da representante da comunidade indígena da TI do Guarita na defesa das demandas indígenas. Também neste nível, sublinha-se a participação, o envolvimento e a pressão das lideranças indígenas - principalmente do Cacique da TI do Guarita - na esfera política manifestada na pressão junto à EMATER, SDR e MDA.

Em nível estadual, destacam-se como empreendedores da chamada pública de ATER: a) o ex-delegado do Desenvolvimento Agrário e depois assessor do Ministro do Desenvolvimento Agrário - empregado da EMATER/RS-Ascar cedido ao MDA, possuía grande acesso ao MDA em Brasília, bem como relação próxima com empreendedores locais/regionais, sendo desta forma, mediador essencial no processo de construção desta política de ATER Indígena; b) a antropóloga da EMATER, em virtude da realização de vários trabalhos acadêmicos na área de ATER Indígena, o que conferia cientificidade à discussão, bem como pela militância junto à diretoria da EMATER pela ampliação de atendimento junto às comunidades indígenas.

Em nível nacional, é notável a atuação de: a) Diretor do DATER, que acolheu e encaminhou o pedido da DFDA/RS para análise preliminar de possível Chamada de ATER Indígena. Posteriormente, coube ao Coordenador de Políticas para Povos Indígenas do CGPCT/MDA e ao Coordenador Geral do CGPCT/MDA fazerem as tratativas junto à FUNAI e ao MDS para construção da Chamada, cabendo ao MDA, principalmente, a confecção do Edital e a alocação de recursos para a chamada pública de ATER. b) Coordenador-geral da Coordenação de Apoio a Povos e Comunidades Tradicionais da Secretaria Nacional de Segurança Alimentar e Nutricional (SESAN/MDS). Ao MDS, cabia a disponibilização de dados referentes ao CadUnico e recursos destinados ao Programa de Fomento. c) Coordenadores da CGETNO, que tiveram um papel decisivo na efetivação da política em duas questões: na emissão das Informações Técnicas 094 e 131/2012, que deram sustentação técnica aos argumentos que embasaram a tomada de decisão referente ao número de famílias e às áreas preferenciais, e a produção teórico-conceitual que embasou a Chamada referente aos princípios de etnodesenvolvimento.

Na figura 1, o organograma apresenta os fluxos, as janelas de oportunidade e a definição da agenda. 
Figura 1 - Modelo dos múltiplos fluxos aplicado ao caso em estudo

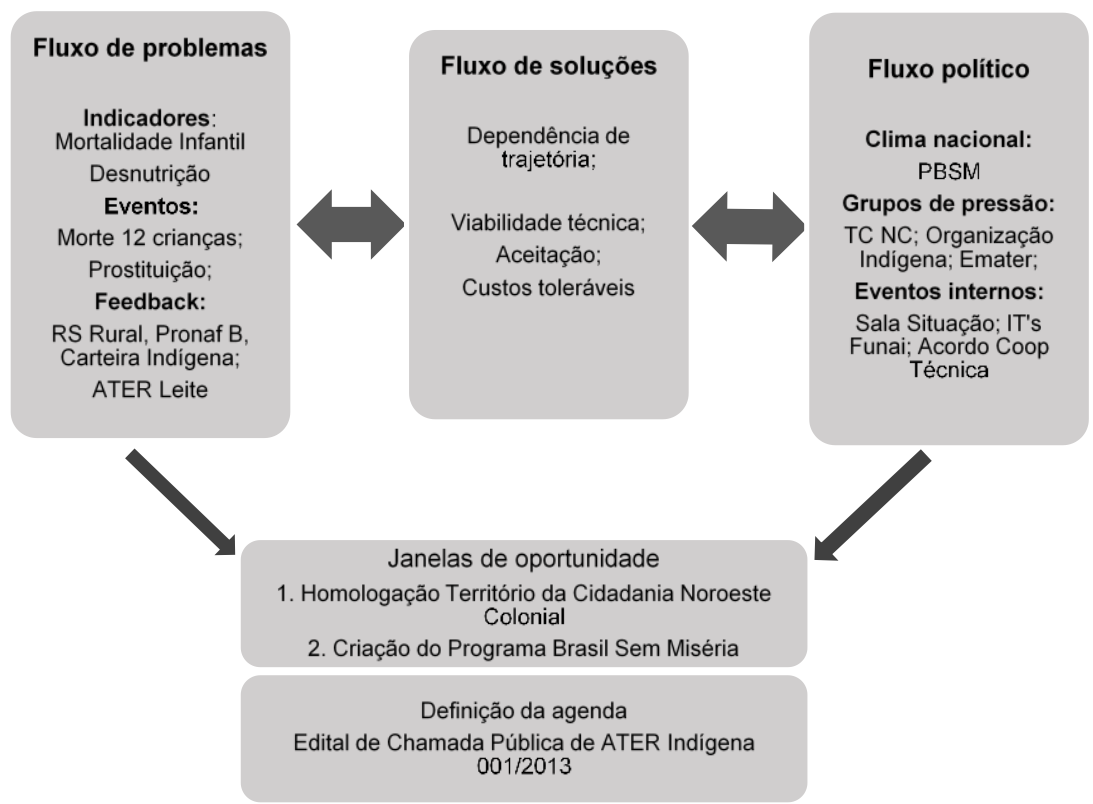

Fonte: Dados da pesquisa

\section{CONSIDERAÇÕES FINAIS}

Consideramos a criação da chamada pública de ATER Indígena uma construção social realizada por muitas mãos e muitas vozes, envolvendo vários níveis de moderação.

Mesmo tendo uma ação governamental direta, por conta das políticas públicas já praticadas e de seus instrumentos, como por exemplo os Territórios da Cidadania e as chamadas de ATER já existentes, além de um aparato institucional consolidado, como MDA, FUNAI e EMATER/RS-Ascar, esta política de ATER Indígena não teria existido sem o protagonismo da comunidade indígena da Terra Indígena do Guarita. Ousaram requerer direitos e acessar uma arena de disputa - o Território da Cidadania Noroeste Colonial - arena esta, permeável a uma participação sociocultural diversa, apoiados por empreendedores em nível local/regional e estadual governamentais e não-governamentais, que souberam o momento certo de acionar a construção deste instrumento da política de ATER.

Como pontos controversos na construção da Chamada, podemos considerar principalmente dois fatores. O primeiro, a exclusão da Terra Indígena do Inhacorá do escopo de terras beneficiárias, visto que esta comunidade participava dos mesmos fóruns de discussão dentro do TC Noroeste Colonial e possui problemas estruturais similares aos da TI Guarita. A sua não-inclusão, por não estar entre os quarenta e um municípios com maior número absoluto de indígenas extremamente pobres no meio rural, causou estranhamento pela comunidade, no entanto, este critério denota a ênfase dada pela política no combate à extrema pobreza, mais do que propriamente ao etnodesenvolvimento, ou a uma política de caráter territorial. O segundo, o fato das definições das atividades a serem 
contratadas na Chamada se dar no âmbito tecnocrático, a partir da visão de especialistas, com participação indígena apenas na audição de elementos à Chamada em oficina de Consulta com lideranças nacionais.

Por fim, entendemos que a luta pelo reconhecimento que os povos indígenas empreendem a cada dia, trouxe como resultado a formulação de políticas públicas mais adequadas às suas necessidades, entendendo este avanço como parte de um longo e complexo processo, do qual as instâncias apropriadas à participação e protagonismo indígena são fundamentais.

\section{REFERÊNCIAS}

ALLEBRANDT, S.L.; DECKERT, C.T.; SAUSEM, J.O. A gestão social no Território da Cidadania Noroeste Colonial do Rio Grande do Sul. VI ENAPEGS, São Paulo, 2012.

BARROS, H. Desnutrição causa morte de 12 crianças índias no sul. O GLOBO, Rio de Janeiro, p. 11, 12 mar. 2001. Disponível em https://pib.socioambiental.org/pt/noticias?id=81455. Acesso em 18 jan. 2017.

BRASIL. Lei $\mathbf{n}^{\circ}$ 12.188, de 11 de janeiro de 2010. Institui a Política Nacional de Assistência Técnica e Extensão Rural para Agricultura Familiar e Reforma AgráriaPNATER e o Programa Nacional de Assistência Técnica e Extensão Rural na Agricultura Familiar e na Reforma Agrária- PRONATER, altera a Lei $n^{\circ} 8.666$, de 21 de junho de 1993, e dá outras providências. Brasília, DF, 2010a. Disponível em https://www.planalto.gov.br/ccivil_03/_ato2007-2010/2010/lei/l12188.htm. Acesso em 10 de junho de 2017.

BERGAMASCO, S.M.P.P.; THOMSON, C.R.; BORSATTO, R.S. Da extinção da Embrater à criação da Anater: os desafios da política de assistência técnica e extensão rural brasileira. In: DELGADO, G.C.; BERGAMASCO, S.M.P.P. (Org.). Agricultura familiar brasileira: desafios e perspectivas de futuro. Brasília: Ministério do Desenvolvimento Agrário, 2017. p. 312-340.

BRASIL. Decreto no 7.747, de 5 de junho de 2012. Institui a Política Nacional de Gestão Territorial e Ambiental de Terras Indígenas - PNGATI, e dá outras providências. Folder. Brasília, DF, 2012a.

BRASIL. Acordo de cooperação técnica. Diário oficial da união, Brasília, DF, 26 de julho de 2012b, p. 109.

CAPELLA, A.C.N. Perspectivas teóricas sobre o processo de formulação de políticas públicas. Revista brasileira de informação bibliográfica em ciências sociais, Rio de Janeiro, n. 61, 2006.

CARDOSO DE OLIVEIRA, R. Ação indigenista, eticidade e o diálogo interétnico. Estudos avançados, v. 14, n. 40, 2000.

CASADO, D.D. Análise da definição da agenda do Programa Nacional de Fortalecimento da Agricultura Familiar (PRONAF) no governo FHC. 2014. Dissertação (Mestrado em Ciências Sociais) - Programa de Pós-graduação em Ciências Sociais, Universidade Federal de São Paulo, São Paulo, 2014. 
DECKERT, C. Configuração do poder no Codeter: uma análise do território da cidadania noroeste colonial-RS. Redes - Santa Cruz do Sul: Universidade de Santa Cruz do Sul, v. 22, n. 1, p. 402-429, janeiro-abril, 2017.

DESNUTRIÇÃO matou 11 crianças. ZERO HORA, Porto Alegre, 09 mar. 2001. Disponível em: http://ti.socioambiental.org/noticia/2576. Acesso em: 09 nov. 2015

FUNDAÇÃO NACIONAL DO ÍNDIO - FUNAI. Política Indigenista. Brasília, DF, 2015. Disponível em http://www.funai.gov.br/index.php/nossas-acoes/politicaindigenista?limitstart=0\#. Acesso em 24 jul.15.

FUNDAÇÃO NACIONAL DO ÍNDIO - FUNAI. Informação Técnica no 094/CGETNO/2012. Brasília, DF, 17 jul. 2012a.

FUNDAÇÃO NACIONAL DO ÍNDIO - FUNAI. Informação Técnica no 131/CGETNO/2012. Brasília, DF, 19 set. 2012b.

HONNETH, A. Luta por reconhecimento: A gramática moral dos conflitos sociais. Tradução de Luiz Repa. São Paulo: Ed. 34, 2003. 296 p.

KINGDON, J.W. Juntando as coisas. In: SARAIVA, E.; FERRAREZI, E. Políticas públicas. Brasília: ENAP, 2006, p. 225-247.

KINGDON, J.W. Como chega a hora de uma ideia? In: SARAVIA, E.; FERRAREZI, E. (Org.). Políticas públicas: coletânea. Brasília: ENAP, 2006. V. 1. p. 219-225.

MELLO, J. O papel das salas de situação na gestão e monitoramento do Brasil Sem Miséria. In: JANUZZI, P. et.al. (Org.) Cadernos de estudos desenvolvimento social em debate, Brasília, DF, n. 25, 2016.

MINISTÉRIO DO MEIO AMBIENTE. Carteira Indígena: moderação da consulta regional aos povos indígenas das regiões Sul-Sudeste e respectivo relatório. Florianópolis, dez. de 2007. 50 p.

MITCHEL, J. Desnutrição mata criança caingangue. Jornal do Brasil, Rio de Janeiro, p. 5, 10 mar. 2001.

PACÍFICO, D. A. Os sistemas locais de ação pública e a sua origem nas redes sociotécnicas: a territorialização do Plano Brasil Sem Miséria Rural. Extensão Rural, Santa Maria, v.24, n.3, jul./set. 2017. Disponível em: https://periodicos.ufsm.br/extensaorural/article/view/20407/pdf. Acesso em: 11 maio 2017.

PESSOA, M. L. (Org.). Regiões do RS. In: PESSOA, M. L. Atlas FEE. Porto Alegre: FEE, 2017. Disponível em: http://atlas.fee.tche.br/rio-grande-do-sul/territorio/regioesdo-rs/. Acesso em 11 maio 2017.

PIERSON, P. Increasing returns, path dependence, and the study of Politics. The American Political Science Review, v. 94, n. 2, p. 251-267, jun. 2000.Trad. PAVARINA, P.R.J.P. Retornos crescentes, dependência da trajetória (Path Dependence) e o estudo da política. Ideias, v. 6, n. 2, p. 335-392, 2016. 
PRINTES, R.; KUBO, R.R.; COELHO-DE-SOUZA, G. A emergente Política Nacional de Gestão Territorial e Ambiental de Terras Indígenas em contextos não amazônicos. V Encontro da Rede de Estudos Rurais. Belém, 2012.

SAMBORSKI, T. A ação extensionista e a pobreza rural: a ATER no Programa Brasil Sem Miséria na região Celeiro do RS. 2016. Tese (Doutorado em Extensão Rural) - Programa de Pós-graduação em Extensão Rural, Universidade Federal de Santa Maria, Santa Maria, 2016.

SOARES, M. A. É possível construir uma ATER indígena diferenciada? O caso dos guarani no estado do Rio Grande do Sul. In: VERDUM, R.; ARAUJO, A. (Org.). Experiências de assistência técnica e extensão rural junto aos povos indígenas: o desafio da interculturalidade. Brasília, DF: NEAD/SAF, 2010.

SOMPRÉ, J. U. Políticas públicas e sustentabilidade: Projeto RS-Rural na Terra Indígena Guarita - Setor Três Soitas. Monografia (Trabalho de Conclusão de Curso em Agronomia), Unijuí, ljuí-RS, 2007.

SOUZA LIMA, A. C. de. Sobre tutela e participação: povos indígenas e formas de governo no Brasil, séculos XX/XXI. MANA, v. 21, n. 2, p. 425-457, 2015.

WAGNER, C. Índias prostituídas. ZERO HORA, Porto Alegre, 08 ago. 2000, p. 3032. 